\title{
¿NO HAY NADA REALMENTE JUSTO? FILOSOFÍA Y POLÍTICA EN EL «DISCURSO PRÉLIMINAIRE» DEL MATERIALISTA LA METTRIE
}

\author{
Miguel Ángel CORDERO \\ Catedrático de Filosofia del INEM. "Ordoño II" de León. \\ Profesor Asociado de Filosofia de la Universidad de León
}

Resumen: La Filosofia, como la medicina, se ocupa de la verdad natural del individuo, que pretende ser feliz. Por el contrario, la moral, cuyo origen está en la politica, no es natural sino convencional, de acuerdo con los intereses sociales dominantes. Pero, aun perteneciendo a diferentes ámbitos, la filosofia puede inspirar a la moral politica el punto de vista del interés general, $y$, por tanto, de una justicia objetiva como campo de juego de las tendencias naturales individuales.

Palabras clave: Filosofia, naturaleza, felicidad, moral, politica, justicia, convención, interés.

Abstract: Philosophy, as medicine, looks after individual's natural truth whose aim is to be happy. On the contrary morals, coming from politics, is not natural but conventional according to social prevailing interests. Nevertheless, even belonging to different fields, philosophy can inspire political morals with the point of view of general interest and so of objective justice as a playground of natural individual tendencies.

Key words: Philosophy, nature, happiness, morals, politics, justice, convention, interest.

Julien O. De La Mettrie (1709-1751) es un médico-filósofo francés no muy conocido, salvo por la imagen provocadora que proyectan algunos títulos de su Obra, como, v.g., "L'homme-machine", "L'homme-plante», "L'Anti-Sénèque", "La Volupté", o "L'Art de jouir". Es un epicúreo radical en una época caracterizada por el aprecio del hedonismo, entre materialistas y no materialistas que valoran las posibilidades de expresión del cuerpo humano frente a su simple sujeción al alma racional, como era usual en el siglo anterior. 
La Mettrie exalta el placer sensorial como parte importante de la felicidad personal que no puede confundirse con utilidades ajenas a las necesidades y deseos individuales, ni desligarse tampoco de su dimensión social en una sociedad justa y tolerante. Base hedonista que le permite adentrarse en un pensamiento materialista opuesto a toda ruptura entre sentido y razón, individuo y naturaleza. De ahí su teoría de la Substancia, contraria a todo dualismo, particularmente el cartesiano, que, a su juicio, compromete la inocencia de la felicidad humana. Alma y cuerpo, hombre y animal son únicamente «modos de ser» de la Substancia viva material que no precisa de entidades o formas espirituales ajenas. La intención filosófica de La Mettrie es la de devolver al ser humano el sentimiento de unidad y reposo en el ámbito de un universo natural armónico y próximo. Recuperar la unidad antropológica en el seno de la unidad cósmica, reprimida por la moral religiosa y política. De ahí la hostilidad entre naturaleza y "moral natural», o, lo que es igual, entre naturaleza e intereses políticos legitimados por dicha moral, reforzada por el peso de la Institución religiosa.

Condenada su «Histoire naturelle de l'âme» (1745) por el Parlamento de París, y exiliado en Holanda, donde se condena igualmente su «L'hommemachine" (1747), debe partir de nuevo al exilio bajo la protección de Federico II de Prusia, monarca Ilustrado que le acoge calurosamente. Y allí publica su "Anti-Sénèque" o "Discours sur le bonheur" (1748) que contrapone vivamente la moral fruitiva de la naturaleza a la ascética de la razón estoica. Nuevo escándalo y nueva censura de publicación.

El motivo del escándalo no es propiamente su teoría materialista general compartida en algunos círculos Ilustrados - sino su aparente cuestionamiento de los nuevos ideales sociales, que minaba la esperanza, albergada por los intelectuales de su tiempo, de romper con las caducas instituciones políticas del antiguo Régimen aristocrático. Por ello, su autor es minusvalorado como un tardolibertino escéptico, inmoral, frívolo e inconsecuente. Así se manifestarán quienes, siguiéndole secretamente en su orientación general, le despreciarán públicamente, para evitar ser confundidos con él: Voltaire, Diderot, D'Holbach, etc. '.

1 "Implicaciones éticas del concepto de "Volupté" en la Obra de J.O. de La Mettrie. Una aproximación al estudio del hedonismo (materialista) en el siglo XVIII francés».

Miguel Ángel Cordero. Tesis Doctoral. Universidad de León, 2000, p 34 ss. 
Todo ello explica que La Mettrie trate de justificar y legitimar, a los ojos de los intelectuales, y a los de Federico II, su posición general filosófica -la de la filosofía y la del filósofo- particularmente en el ámbito político, negando que la filosofía ponga en peligro la estabilidad del orden social, conformado básicamente por la legalidad política y sostenido por la creencia religiosa y el sentido ć́vico del deber. El filósofo Ilustrado de mediados de siglo no es ya el "honnête homme" retirado del bullicio, sin ambiciones ni prejuicios, ni el sutil "homme d'esprit», sino el intelectual que discute los fundamentos del poder y se preocupa por el desarrollo social y económico, al tiempo que critica usos y costumbres.

El texto de justificación es el "Discours Préliminaire» (1751) concebido como Introducción a su Obra filosófica ${ }^{2}$, cuyo comienzo es toda una declaración de principios:

«Me propongo probar que la filosofia, por contraria que sea a la moral y a la religión, no sólo no puede destruir esos dos lazos sociales, como se cree habitualmente, sino únicamente estrecharlos y fortalecerlos cada vez más» ${ }^{3}$.

Declaración paradójica. ¿Qué entiende La Mettrie por filosofía y por moral?. Seguidamente añade:

«La filosofia, a cuyas investigaciones se somete todo, se encuentra sometida, a su vez, a la naturaleza, como una hija a su madre. En común con la verdadera medicina, considera esta esclavitud como un honor, sin conocer otro, ni escuchar otra voz. Todo cuanto no se extrae del seno mismo de la naturaleza, todo cuanto no es fenómeno, causa, efecto, ciencia de las cosas, en una palabra, no tiene nada que ver con la filosofía, y se origina en una fuente que le es ajena. Ése es el caso de la moral, fruto arbitrario de la política ..." ${ }^{4}$.

Dos ámbitos bien diferentes, pues. La filosofía, al igual que la medicina, se ocupa de los fenómenos naturales en lo que atañe a la relación entre cuerpo y alma, o entre individuo y naturaleza. En este texto La Mettrie no quiere pen-

2 El "Discours Préliminaire" formaba inicialmente parte de la «Histoire Naturelle de l'Âme" (posteriormente "Traité de l'Âme») de donde La Mettrie lo extrae en 1751 como un rexto autónomo que presida su Obra filosófica, y sirva, a un tiempo, de introducción y justificación de su filosofía materialista.

3 LA METTRIE: “Oeuvres philosophiques», vol I. (D.P.). Paris, Fayard, 1984, p 9.

4 LA METTRIE: Ibidem. 
sar la diferencia entre filosofía y ciencia, o, mejor, no establece diferencia en lo que respecta a su común origen, el del ser natural, frente al deber-ser de la moral, o sistema de las costumbres políticas, que garantizan el comercio social entre los hombres. Teniendo su origen en la política, como las leyes y las sanciones, la moral no es obra de la naturaleza, por más que se la califique de "natural", y, por consiguiente, nada tiene que ver con la filosofía. Esta se ocupa de la verdad y aquélla pertenece al campo de la convención arbitraria —cuya finalidad legitimadora apenas disimula su carácter ilegítimo de efecto interesado- La moral verdaderamente natural no es otra cosa que la invitación de la naturaleza a seguir sus propias inclinaciones, reprimidas por la moral política, atenta a intereses de otro orden.

La verdad del filósofo no guarda parentesco con la justicia del legislador, pues no mide las consecuencias sociales de los actos que conforman lo que La Mettrie llama el "error social interesado", una especie de "doble verdad", cuyo fundamento no se encuentra en la naturaleza, sino en la utilidad y beneficio del todo social, forzosamente sometido a la convención y evolución propias del ámbito de las costumbres, tan relativas como el entramado "comercial" al que sirven.

La verdad es absoluta y el error relativo. Por eso, es posible conciliarlos sin confundirlos. La Mettrie afronta la objeción de que si la filosofía se opone a las convenciones sociales, dogmas y costumbres, entonces contribuye a romper los lazos que vinculan a los hombres entre sí, minando los fundamentos de la política. Responde a la objeción de un doble modo: negativamente, ya que la política nada debe temer de la crítica filosófica (2. ${ }^{2}$ Parte del Discurso), y positivamente, pues política y moral pueden aspirar a su propia reforma bajo la inspiración de la filosofía (3. Parte).

Que la política nada deba temer de la filosofía se deduce claramente del reconocimiento mutuo de su autonomía respectiva: la investigación de la verdad no impide la necesaria aceptación de la utilidad social. Aquélla goza de una capacidad de destrucción meramente hipotética, que no hace mella especial en un pueblo ignorante, y que no convierte al filósofo incrédulo en un enemigo de la verdad establecida. El profesional empírico de la verdad es flexible y comprensivo con el error necesario, basado en prejuicios e imposiciones. Escribe La Mettrie:

"No hay nada absolutamente justo, nada absolutamente injusto. Ni equidad real, ni vicios, ni grandeza, ni crímenes absolutos. Políticos, líderes 
religiosos, conceded esta verdad a los filósofos ... admitid de buena fe que es justo quien pondera la justicia, por así decir, con el peso de la sociedad ... y, a su vez, los filósofos os concederán (¿cuándo os lo han negado?) que tal acción es relativamente justa o injusta, honesta o deshonesta, viciosa o virtuosa, laudable, infame, criminal, etc.; ¿quién os discute la necesidad de todas esas bellas relaciones arbitrarias?" ${ }^{5}$.

Texto contundente y sorprendente, que pone en tela de juicio la moral «natural», y que, como otros textos similares, le ha reportado a La Mettrie el anatema de escandaloso. El texto invita a no caer en falacia naturalista, mezclando la moral con la naturaleza. Introduce el principio de relatividad en la moral, reconociendo que ésta pertenece al relativo campo de la política, al igual que la religión. Campo erróneo sólo si se compara su valor de verdad con el de la naturaleza, pero necesario en la medida en que los hombres han de respetar puntos de referencia que rijan la convivencia, y que se ve reforzado por la sanción oportunamente prevista para el incumplimiento de los mismos. Religión y moral son instancias interiorizadas, para evitar la «elevación por el cadalso».

Como el movimiento en Galileo, las nociones de lo justo, honesto, virtuoso, etc..., en La Mettrie, no remiten a realidad alguna definible por sí misma, sino a un punto de referencia que no ofrece mucha garantía de estabilidad en un terreno tan movedizo como el de las valoraciones político-morales. Repite con frecuencia que él no declama, ni moraliza, sino que explica:

«No se diga, de ninguna manera, que yo invito al crimen; tan sólo invito a la paz en el crimen" 6 .

Si la naturaleza determina nuestros actos, no somos libres, en absoluto, de contravenir una norma moral relativa, aun cuando la sociedad pueda, y deba, en su defensa, sancionarnos con toda su fuerza. Pero no tiene sentido privar al delincuente de su inclinación natural al reposo interior, introduciendo en él remordimientos por la conculcación de una supuesta norma «natural».

Se trata de delimitar bien los campos y de que sus respectivos profesionales pacten un acuerdo posible. El filósofo reconoce la necesidad de una justi-

5 LA METTRIE: o.c., I (D.P.) p 24-25.

6 LA METTRIE: o.c., II (D.B.) p 287. 
cia relativa como concesión a un poder que fomenta en los débiles, por igual, la esperanza y el miedo, vías eficaces de imposición de un orden social. Él mismo dice preferir la verdad como filósofo y el error como ciudadano, pues uel error está más al alcance de todo el mundo como alimento general de los espíritus en todo tiempo y lugarm.

La ironía de esta concesión no podía engañar fácilmente a Federico ni a la Corte. Sobre todo, por el giro que toman los argumentos en la tercera y decisiva parte del Discurso, olvidado el tono cauteloso de la anterior.

Es ahora cuando se precisa la expresión del "peso de la sociedad", al definir el ámbito de la justicia como algo más que un mero punto de referencia. Se trata de algo intermedio entre los ámbitos de la naturaleza y de la política. Dice La Mettrie:

“Por más que la retórica dé a las leyes, o a los actos más injustos, un aspecto de equidad y de razón, la filosofía no se engaña al respecto, pues tiene un punto fijo para juzgar acertadamente sobre lo que es honesto o deshonesto, equitativo o injusto, vicioso o virtuoso, descubriendo el error y la injusticia de las leyes» ${ }^{7}$.

Desaparece toda ambigüedad: el error social es necesario sólo en relación con el caos o la guerra general. Más vale que haya leyes, aunque sean injustas, como había adelantado Montaigne. Misión de la retórica es barnizarlas, volviéndolas razonablemente presentables, aunque la filosofía no se deje engañar. Así se hace preciso un nuevo saber que delimite con claridad la naturaleza de la política, y la moral de ambas. Ni la ley es, sin más, verdadera, ni la verdad es siempre aceptada o comprendida. Entre el interés natural del individuo y los intereses artificiales de los grupos la razón encuentra un tertium quid, el interés de la sociedad, objetivo, universal, verdadero punto fijo como cruce de los intereses naturales.

La filosofía no puede imponerse directamente sobre usos, costumbres y leyes, por erróneos o injustos que sean. En ese sentido, no es peligrosa, no mina las bases de la convivencia política. Pero indirectamente aspira a conjuntar justicia y verdad, influyendo en la educación de los dirigentes políticos, con

7 LA METTRIE: o.c., I (D.P.) p 37. 
su punto fijo de referencia universal, que convierte lo «justo" legal en lo justo racional, y la virtud socialmente conveniente en virtud comprometida con las necesidades reales. El pueblo será más fácil de conducir, si quienes detentan el timón del Estado confían más en la filosofía y menos en la retórica. Frente a la sagesse como astucia política, la sagesse como prudencia y equidad que subordina la utilidad social a la libre expresión individual. La virtud de la tolerancia, reivindicada en su "Discours sur le bonheur", exige del poder establecido que comprenda, al menos, los límites de toda represión. El poder ha de defenderse del exceso criminal, pero no debe sofocar las tendencias biológicas inevitables. La sociedad es el campo de juego de las distintas "Organizaciones» biológicas, no la meta o fin de éstas. Más allá de la tolerancia, que debe regir las relaciones del poder con los súbditos, está la virtud de la justicia, que no depende del tacto reclamable al poderoso, sino de la fija posición de la razón. El ámbito social de la legalidad da el derecho, pero éste no es ya razonable por sí mismo, sino coactivo, aplastando con frecuencia al miserable que tiene la razón. Las leyes, no siendo forzosamente justas siempre, han de ser rectificables, y no desde la tolerancia concesiva, sino desde un punto objetivo de referencia que ellas mismas no tienen y han de pedir a la filosofía.

En el "Discours sur le bonheur" insiste La Mettrie en la virtud de la tolerancia con el criminal que no puede evitar su determinación natural; no con el crimen, sino con el sufrimiento del delincuente agobiado por un inútil complejo de culpa. En el "Discours Préliminaire», que es posterior, La Mettrie va más lejos. No habla de tolerancia, sino de justicia; no apela al sentimiento, sino a la razón:

"Cuanto más filósofos sean los príncipes, o sus ministros, tanto más capaces serán de sentir la diferencia esencial que se encuentra entre sus caprichos, su tiranía, sus leyes y su religión, y la verdad, la equidad y la justicia. Y, por tanto, cuando más sirvan a la Humanidad ... más cerca estarán de conocer que la filosofía, lejos de ser peligrosa, sólo puede ser útil y saludablen ${ }^{8}$.

El cambio en relación con los textos antes aludidos es manifiesto. Gracias a la acción de la razón en la mente de los dirigentes, la moral no forma ya parte 
del ámbito erróneo en el que se encuentran la religión y la política, que pierden su legitimidad aparente y se exhiben como tiranía y capricho de los poderosos, como su religión y su política, esencialmente diferentes de la verdad y justicia universales. Si el complejo religioso-político-moral conformaba el erróneo orden necesario que el filósofo debía comprender en aras de la utilidad social, en adelante verdad y justicia, al servicio de la humanidad, son el verdadero ámbito de la salvación social.

¿Verdadera justicia, justicia verdadera?

La justicia, en sí misma, nada tiene que ver con la naturaleza, y, por tanto, con la verdad. Pero, como posición de la razón, y no del mero capricho, es condición de posibilidad de la verdad natural, y del respeto a la misma, por parte de las leyes, que ya no podrán ser erróneas o injustas, pues su necesidad es anterior a cualquier interés puramente privado. Frente al error social necesario, hay que hacer valer la verdad social, o, lo que es igual, la necesidad social de manifestación de la verdad natural. Así, el Discurso pasa de la justificación aparente de una filosofía neutral ( $2 .^{a}$ parte) a la justificación real de una filosofía comprometida, capaz de legitimar la política ( $3 .^{2}$ parte).

La conclusión presenta la forma de una doble exhortación: a los poderosos, para que ejerzan su razón en bien de la sociedad; y a los filósofos, para que se enfrenten con el fanatismo teológico y con sus propias ambiciones hipócritas. Brillante exhortación, sincera, audaz y enérgica, que aúna elocuencia con independencia de pensamiento - postulada, a la vez, como meta del filósofocon el aval de su propio riesgo personal en la defensa desinteresada de la verdad y de la libertad:

"Quien sacrifica los dones preciosos del genio a una virtud política, trivial y limitada, como son todas, ya puede decir que ha convertido su espíritu en estúpido instinto y su alma en sórdido interés ... Seamos, pues, libres en nuestros escritos como en nuestros actos; mostremos en ellos la orgullosa independencia de un republicano. Un escritor tímido y circunspecto, no valiendo para la ciencia, ni sirviendo al espíritu humano, o a su patria, se pone a sí mismo obstáculos que le impiden elevarse ... es preciso que un filósofo escriba con noble arrojo, o que cuente con reptar como aquéllos que no lo son" ?. 
¿Puede sostenerse, acaso, que éste es el Discurso de un fingidor o de un hipócrita?. ¿O de un arribista ambicioso?. La Mettrie, no se olvide, es un refugiado protegido por el rey. Pues bien, ¿qué refugiado se atreve a proclamar la "orgullosa independencia de un republicano" en casa del autócrata, por Ilustrado que éste sea?. El virtuosismo político - $\tan$ corto de alcances e impropio del genio - nada tiene que ver con su propuesta de virtud racional. Sólo es libre quien es independiente merced a su razón, el filósofo, que nada tiene que ver con los sórdidos intereses de un cortesano.

Ahora bien, ¿qué pensaba de todo ello Federico? ${ }^{10}$. ¿Concretamente de la relación entre política y moral?.

A pesar del "Antimaquiavelo" de su juventud, Federico II reconocía la escisión entre moral y política —o filosofía y política, pues la filosofía se ocuparía, sobre todo, de problemas morales-, de modo que las cualidades morales del filósofo - moderación, humanidad, justicia y tolerancia- entran en conflicto inevitable con las responsables exigencias del estadista que ha de velar por las consecuencias favorables de su empresa, consultando con su propio interés. El ejercicio del poder pone de relieve la tensión creciente entre ser y deber, espíritu y corazón, intereses del pueblo y respeto a los tratados ${ }^{11}$.

Su visión de la realidad no es la propia del médico, ni la del filósofo naturalista; en suma, no es la de su protegido La Mettrie, con quien no podía coincidir sino en sus desahogos irreligiosos y libertinos, que, en modo alguno, podían confundirse, ni interferir, con la apremiante urgencia del juego político.

En La Mettrie, lo real es la demanda de la naturaleza racionalmente comprendida desde el punto fijo del interés de la sociedad frente a las pretensiones particulares de la virtud política siempre limitadamente interesada y trivial.

Federico, en cambio, no tiene ojos para otra realidad que la del interés político particular, crecientemente enfrentado, eso sí, a las apelaciones de la conciencia moral, relegadas al ámbito privado. La moral no rebasa la intención subjetiva de la tolerancia humanitaria bajo el principio del amor pro-

10 Federico II de Prusia, protector de La Mettrie en su exilio en Prusia, redactó un Elogio fúnebre a la muerte del filósofo, que contiene el resumen de su vida y una defensa de su actitud como médico y filósofo, en lucha contra la superstición y a favor de la verdad.

11 Federico II en "Histoire de mon temps». Citado por R. Aramayo en "La Quimera del Rey Filósofo». Madrid, Taurus, 1997, p 71 ss. 
pio, entendido por Federico como epicúrea serenidad y tranquilidad de ánimo que nada se reprocha y de nada se arrepiente. Moral de "Sans Souci” ${ }^{12}$.

Remordimiento y arrepentimiento son conceptos a tener muy en cuenta en la filosofía moral de La Mettrie ${ }^{13}$, pero son únicamente rémoras de una educación basada en el prejuicio de origen social, y de inspiración política sobre la base del dualismo irreductible entre inclinaciones naturales e intereses artificiales. Superado el dualismo, se obtiene la convergencia entre individuo y sociedad que elimina objetivamente todo motivo de conflicto. En Federico, por contra, el camino es el inverso: de una bienintencionada crítica juvenil al dualismo de Maquiavelo entre moral y política va pasando progresivamente a la reconciliación son su posición. Moral e intereses divergen entre sí de modo necesario, sin reducción posible del uno al otro, quedando el interés común a merced de los dictados del interés político, aun cuando permanezca el rescoldo inextinguible del alma bella. No es La Mettrie, sino Federico, quien debiera recibir la acusación de minar los fundamentos del orden social, pero el destino quiere que sea el filósofo quien deba asumir la carga de la prueba de su inocencia política.

Los comentaristas de La Mettrie tienden a poner de relieve el lado cínico de una filosofía, que, o bien se desentiende de la política, o bien acepta acríticamente cualquier política, incluso la despótica, cuando no es posible conducir a los hombres según las luces naturales de la razón.

Vartanian lo compara con Diógenes, pues exhibe su propia desnudez como medio de desnudar a los demás. El hombre se convierte en mono ante el espejo, detrás del cual no está el hombre sólido que esperaba encontrar, sino la pura nada. Parece que el espejo le devuelve su propia imagen mejorada como la imagen de la humanidad que cubre su desnudez natural con el velo de la dignidad espiritual, divina e inmortal, pero todo es una ilusión tácita e interesadamente consentida que La Mettrie denuncia, provocando el escándalo ${ }^{14}$. La filosofia es lúcida, aunque los intereses del poder utilicen espejos distorsionadores de

12 "Sans-Souci" es el nombre del Palacio de verano de Federico. En él se estudiaba la moral epicúrea de Lucrecio.

13 M.A. CORDERO: o.c., p 221 ss.

14 A. VARTANIAN: "Le philosophe selon La Mettrie», en "Dixhuitième siècle", 1, 1969, P 170 ss. 
la realidad. Como el sobrino de Rameau, La Mettrie exhibe impúdicamente su locura e inmoralidad, su frivolidad política.

Ann Thomson encuentra contradicción entre "las dos partes del Discurso". La primera muestra la total separación entre la filosofía, de una parte, y la moral, religión y política, de otra. La segunda parte, en cambio, pretende hacer valer la utilidad de la filosofía en el ámbito que le es ajeno, pretensión que ella atribuye a la necesidad en el filósofo de ganarse al auditorio de la Corte. Dado que el pueblo no se atiene a razones y es insociable, según La Mettrie, deberá ser guiado coercitivamente por cualquier forma de gobierno, incluso despótico. Expresión que no aparece en La Mettrie, pero que, según ella, debería extraerse de su posición cínica y elitista general. El individualismo y libertinismo aristocrático de La Mettrie no encontraría otra sutura con los intereses de la sociedad que la «feliz constitución biológica» del filósofo reconocedor de la necesidad de un orden social, que no es, desde luego, la constitución de que dispone el pueblo ignorante ${ }^{15}$. Y la educación para compensar la deficiencia biológica, según J. Ehrard, no sería otra cosa que la creación de automatismos mentales condicionadores, técnica de propaganda - no de convicción- que es el arte de volver dóciles a los hombres ${ }^{16}$.

P. Rétat confiesa, sin embargo, que:

"Su proyecto es el de esbozar una interpretación de la moral de La Mettrie más matizada que la que se suele ofrecer ... el corazón de La Mettrie no cesa, en sordina, de dictarle opciones y modos de conducta que contradicen el aparente cinismo de sus propuestas sobre la felicidad. Hay que reparar en estas aspiraciones y acentos inseguros, para descubrir un La Mettrie más verdadero y complejo, $y$ asignarle así su lugar en la evolución del pensamiento de las Luces" ${ }^{17}$.

P. Rétat se apoya en unas líneas del Discurso en las que La Mettrie, exculpando a los filósofos en general, y a sí mismo en particular, de toda acusación de subversión, reconoce que:

15 A. Thomson: "La Mettrie’s Discours Préliminaire». Critical edition. Genève-Paris, Librairie Droz, 1981, chap. V.

16 J. EhrarD: "Lidée de nature en France à l'aube des Lumières». Paris, Flammarion, 1970, p 238-239.

17 P. RETAT: «Le coeur de La Mettrie», en «Travaux de linguistique et de littérature», Vol. 13, n. 2, 1975, p 534. 
"No tengo mal corazón ni mala intención que reprocharme; y, si mi espíritu se ha extraviado, para eso está; mi corazón, más dichoso, no se ha extraviado, en modo alguno, con él" ${ }^{18}$.

La lectura de P. Rétat es ingenua, como si La Mettrie reconociera una vía de autosuperación (de su cinismo) en sus sentimientos. De una parte, la razón lúcida destruye el cuadro social de valores, y, de otra, la razón sensible comprende la necesidad práctica de la legislación. Gracias a ésta última, La Mettrie superaría la visión simiesca, puramente naturalista, del ser humano, de que hablaba Vartanian. El cinismo político expresaría más bien un pesimismo profundo sobre la difusión de las Luces que un enjuiciamiento de las mismas. La Mettrie no es un cínico, subraya Rétat, como no lo es el sabio que comprende y consiente la disciplina social necesaria, aunque la mayoría de los hombres deban ser domados por la política. La lucidez no contradice su confianza mesurada en la dignidad del hombre.

Así pretende salvar a La Mettrie de la acusación de cínico Antiilustrado ${ }^{19}$, reconciliándole con las Luces. No distingue su sociabilidad cordial de su coherente posición crítica con los prejuicios que se oponen a la verdad de la naturaleza.

"La ley del sabio es la de plegarse a los prejuicios de su tiempo",

dice Rétat.

«Escribid como si estuvierais solo en el universo, o como si nada tuvierais que temer de los celos y prejuicios de los hombres, o fallaréis el blanco",

dice La Mettrie ${ }^{20}$.

La visión de Rétat no es comprensiva sino blanda, dejando intacto el cinismo que pretende matizar. No ve la posible mediación entre la razón sensible y la lúcida, como si la posición de ésta última fuera meramente hipotética. La fuerza crítica del "corazón de La Mettrie» es precisamente la que inspira el

18 LA MetTrue: o.c., I (D.P.) p 32.

19 Así lo ve, v.g. G.A. ROGGERONE en su «Controilluminismo. Saggio su La Mettrie ed Helvétiusm. Lecce, Milella, 1975.

20 La Mettrie: o.c., I (D.P.) p 47. 
hallazgo de la verdadera justicia en el interés común de la sociedad, que no puede estar lejos de la verdad natural, y sí de intereses extraños y artificiales.

J. Falvey sí tiene en cuenta el naturalismo individualista de La Mettrie, que no debe confundirse con un cinismo despreocupado de toda inquietud social. Su lectura del Discurso reivindica la importancia de la libertad de la filosofia y del filósofo, próximo éste al médico en el alivio de todo factor de terror que pueda reprimir la conducta de cada cual. El verdadero interés de la sociedad exige libertad de creencias, pensamientos y expresión, con la mínima intervención estatal posible, y ninguna de los ideólogos habituales, sean moralistas o teólogos, inductores del terror interior, paralelo al terror externo de la sanción legal. Régimen de libertades que Falvey denomina anarquismo, aunque ni el término, ni el concepto, se encuentren en La Mettrie, el cual propicia una reforma desde arriba, desde una élite que comprenda y acepte la justicia equitativa como fin del Estado, ya que es impensable la solidaridad espontánea del pueblo, o el levantamiento revolucionario.

Pero el naturalismo individualista no es forzosamente anarquista. A pesar de ello, la posición de Falvey tiene la ventaja de despejar la acusación de cinismo libertino que inhabilitaría a La Mettrie como pensador Ilustrado. Efectivamente, es un pensador político, en tanto en cuanto la imprescindible reforma médica exige una ambiciosa reforma política, en lucha contra las trabas ideológicas, corporativistas e institucionales que impiden al ser humano su desarrollo natural ${ }^{21}$.

¿Es La Mettrie un libertino o un Ilustrado?.

¿Ha habido algún libertino que exalte, acaso, la orgullosa independencia de un republicano?. Ciertamente, en sus temas, y en su orientación neospinozista, La Mettrie es heredero de la tradición libertina - frecuentemente clandestinadel s. XVII, liberadora de prejuicios religiosos, políticos o morales, pero no hereda su distante aristocratismo, ya que todo su empeño estriba en reclamar la oportuna reforma política como horizonte inexcusable de toda felicidad universal.

En esa disyuntiva, que se pretende exclusiva, se ha querido encerrar a $\mathrm{La}$ Mettrie. Por mi parte, concluyo poniendo de relieve la posibilidad histórica de

21 J. FalveY: «La Politique textuelle du Discours Préliminaire: l'anarchisme de La Mettrie», en "Corpus", n 5-6, 1987, p 27-52. 
una Ilustración alternativa que apenas pudo ver la luz, la cual no acepte subordinar el placer a la utilidad, ni la naturaleza a los intereses particulares del momento. Una Ilustración hedonista que, a mediados de siglo, fue considerada incompatible con los ideales urgentes de aquel tiempo. En su lugar, triunfó la Ilustración virtuosa, cuyo concepto de justicia universal no coincide precisamente con el de La Mettrie. El interés de la sociedad no es una abstracción políticamente interpretable por el Poder, sino el título que acredita la atención equitativa a las diferencias orgánicas de los individuos. No es un concepto tomado en bloque, al modo utilitarista, que subordina los fines individuales a un sospechoso fin social incontrolable, sino un concepto pluralista al servicio de los individuos, cuyo placer y felicidad se abren a los de la Gran Familia Humana. La misión de los poderosos no consiste en ajusticiar la felicidad, sino en volver placentera la justicia, vista ésta desde la tolerancia, que no es una simple virtud bienintencionada y limitada, como creía Federico, sino la antesala de un nuevo concepto que exige respetar las tendencias naturales de cada cual, compatibles con el respeto de unos por otros. La paradoja es tener que encomendar al poderoso una justicia que no se confunda con la Razón de Estado. 